\title{
Mesa redonda post-La Haya
}

Como parte de su cometido de difundir los temas vinculados con las relaciones internacionales, periódicamente Estudios Internacionales congrega a especialistas en torno a una mesa en que, de manera informal y totalmente abierta, se comentan y discuten problemas y temas de actualidad, con el compromiso de dar a conocer luego en la revista las ideas surgidas a lo largo de las conversaciones. La experiencia ha dado muy buenos resultados y hasta ahora se han desarrollado interesantes debates, por ejemplo, sobre las elecciones presidenciales en los Estados Unidos o los desafíos que enfrenta nuestro país en materia de energía. En rigor, en un mundo globalizado en que los problemas de un país o región se dejan sentir en el resto del orbe, sobran los temas de discusión y a veces centrarse en uno solo podría incluso resultar miope. Entonces, lo aconsejable es optar por alguno que parezca tener grandes proyecciones, sea en la economía, la política, el derecho, la cultura, o ellas en su conjunto. Así nos pareció el caso del fallo pronunciado por la Corte Internacional de Justicia de La Haya, recaído en el diferendo entre Perú y Chile sobre el límite marítimo y dado a conocer a fines de enero pasado. Transcurridos varios meses, el fallo propiamente tal ha sido examinado ya en diversos foros académicos, de manera que no tenía mucho sentido intentar un nuevo análisis jurídico y se optó por abordar su contenido en el marco más amplio de la política exterior de Chile en general y de las impresiones de sus participantes acerca de sus proyecciones en la política vecinal y regional. Esta ampliación del ámbito del análisis enriqueció la discusión y dio lugar a apreciaciones vinculadas a aspectos vitales de esta relación, en que se dieron coincidencias y desacuerdos. Sin embargo, estos últimos no lograron opacar el hecho de que las dos partes involucradas están firmemente comprometidas con el cumplimiento del fallo. 
A continuación, se presenta una reseña de lo expresado en esta mesa redonda organizada por Estudios Internacionales en el orden de intervención de cada participante. 


\section{MARÍA TERESA INFANTE}

(Coagente de Chile en el diferendo entre Perú y Chile ante la Corte Internacional de Justicia, Embajadora de Chile ante el Reino de los Países Bajos, académica de la Universidad de Chile)

En esta mesa coloquial nos reunimos para intercambiar ideas y posiciones, no para hablar como si se tratase de proclamar teorías y escuchar nuestras propias convicciones. Por esto, comienzo por una reseña de cómo situaría el fallo de la Corte Internacional de Justicia de enero pasado en las relaciones bilaterales entre Chile y Perú. Ahora ya conocemos el pronunciamiento del tribunal y las partes se están aplicando progresivamente para su ejecución en diferentes esferas; por ello, es útil reflexionar sobre lo que significó el caso para Perú y Chile.

Para Perú, a demanda tenía caracteres claros de un caso de revisión del statu quo; sus ribetes históricos eran inocultables. Si bien este statu quo no era particularmente negativo para el país vecino, y hasta hace pocos años no se mencionaba en documento alguno como produciendo un efecto negativo en la capacidad marítima peruana, crece cierto resentimiento desde el punto de vista político, que con el tiempo fue adquiriendo ribetes jurídicos. Al mismo tiempo, como puede comprobarse en la doctrina escrita peruana y en los discursos de políticos y comentaristas, parecía existir en Perú una sensación de que había algo pendiente con Chile y de que era preciso abrir un nuevo camino para resolver lo que se consideraba uno de los nervios del corazón, si bien no todo el tema.

No obstante que no era la primera vez que emergía un ambiente semejante en las relaciones bilaterales, se puede observar el sello orientador que Perú dio a la demanda, y que 
llegó a impactar en una parte sustantiva de la relación bilateral. En el curso de los años se observaron varias situaciones en que episodios críticos menores adquirieron una importancia inusitada para las relaciones bilaterales, el más destacado de los cuales fue el momento de adopción y promulgación de la Ley de Arica y Parinacota, el año 2007. En esa oportunidad se puso de manifiesto de qué manera todas las ideas, teoría y propuestas se volcaron hacia una forma de apreciar la relación con Chile.

A su vez, Chile respondía de manera negativa a la búsqueda de reequilibrios por parte de Perú Finalmente, en la parte chilena emergió una mirada confundida en el sentido de que, por una parte, se creía en la renovación de la relación, pero se lamentaba la frustración por un episodio que parecía no entender y que al querer explicar, empeoraba de fisonomía. Chile advertiría después que su contraparte no compartía el mismo enfoque respecto de la relación en el ámbito de esos temas y que todavía no podía hablarse de países con intereses iguales.

En Chile, la mirada sobre el límite marítimo no encontraba muchos puntos en común a ser compartidos con Perú, si bien hay indicios de que se buscaba distinguir entre la demanda y el resto de la relación. Así lo reflejaban varios actores políticos y una persistente búsqueda de racionalización sobre el sentido de esta relación vecinal. Era claro que para los chilenos, la demanda tenía que ver con la modificación de un statu quo que había sido acordado por ambos países.

En tal coyuntura, Chile planteó que no iba a argumentar sobre la posición peruana por una vía que no fuera jurídica, cosa que a algunos comentaristas les costaba entender, porque pensaban que una respuesta jurídica puede estar desprendida de una decisión política y mostrarse aislada de un respaldo político. Para Chile - se observa en sus discursos fundamentales- no estaba en juego el conjunto de la relación bilateral entre ambos países; y si el caso era llevado ante un tribunal internacional había que entrar a discutir con fuerza acerca del nivel de acuerdo existente entre ambos países y afirmar que este se encontraba vigente. Era reconocible una asimetría en la forma en que ambos países evaluaban el límite, cosa que no es raro que se dé en el derecho internacional. Ocurre en 
algunos casos en que los países mantienen un desacuerdo sobre el alcance de un acuerdo determinado pero siguen trabajando por otras vías. A mi juicio, esto lleva a rafirmar la importancia de observar cómo se posicionan los actores en el contexto de una demanda que se avecina y después se concreta ante un tribunal internacional.

Ahora, una vez dictada la decisión de la Corte, se generaron elementos renovadores o innovadores que antes no estuvieron presentes por la interferencia de esos enfoques de revisión del statu quo. Lo que se denominaría continuar avanzando con Perú, concepto sobre el cual puede profundizarse en el debate que, a su vez se compone de elementos que también vienen del pasado, siendo la aceptación de una realidad limítrofe uno de los puntos más importantes para concretar nuevos acuerdos. En esta etapa, todavía de crecimiento y gestación, se manifestarán elementos vinculados directamente a la decisión de la Corte Internacional de Justicia de enero de 2014, pero también habrá otras áreas en que el proceso se desarrolle en forma no linal, con avances y retrocesos. Nuevamente, el discurso y la intención serán fundamentales.

Coincido con lo que se ha dicho en el sentido de que a veces es difícil comprender las razones que mueven las relaciones entre los países; como si hubiese vías paralelas y no se pudiese entender las racionalidades del otro en una negociación, en una simple reunión o ante una agenda de trabajo. Por otra parte, los tiempos de los gobiernos son distintos de los de las comunidades: muchas veces ambos trabajan como si se tratase de coyunturas diferentes. Por otra parte, los gobiernos no siempre pueden introducir en su trabajo elementos o fenómenos que se proyecten en el mediano o largo plazo. Además, los gobiernos no son simétricos entre sí, y obedecen a procesos doctrinarios o decisionales diferentes. Es muy difícil modificar los patrones con los cuales se ve la realidad y a veces esta debe asumirse. En 1999 Chile y Perú negociaron, por tercera vez en pocos años, cómo habrían de ejecutarse algunas disposiciones del tratado de 1929 y su protocolo complementario. Las consecuencias de esa negociación se asimilaron de manera diferente en Chile y Perú. Así, algunas frases pronunciadas en el Perú por internacionalistas históricos, podrían hacer pensar que consideraban que la negociación había sido de poca envergadura. Esto revela 
que tenemos que aprender a trabajar con una realidad cuyos elementos no dominamos totalmente.

Por otra parte, no comparto la tesis de que estamos ante una agenda detenida. En Chile hay un gobierno nuevo e incorporar elementos de la agenda más reciente, que a su vez se une a matices de otros temas de política exterior, todavía parecen no debidamente apreciados en la parte peruana. Hay signos objetivos de que esa relación se sigue estructurando y tiene elementos que pueden crecer, si bien serán posiblemente puestos a prueba. Elementos de este orden son los del derecho del mar, donde puede haber definiciones interesantes. Por ejemplo, en cuanto al contenido de las libertades de la zona económica exclusiva o el acuerdo de cooperación regional del Pacífico Sur. Hay otra áreas donde se refleja la relación bilateral en lo relativo a demandas bolivianas, pero es un tema sobre el cual no me extenderé y cuyos alcances podemos apreciar leyendo notas del pasado.

Perú y Chile han tenido que hacer opciones en ciertas etapas, para generar bases de sus recíprocas relaciones, lo cual se ha traducido en políticas más permanentes y cercanas. Los frutos de estos esfuerzos se comprueban, por ejemplo, en la relación entre Tacna y Arica, y en diversas otras áreas, económicas y sociales.

\section{BEATRIZ RAMACCIOTTI}

(Ex embajadora del Perú ante la Organización de los Estados Americanos, doctora en derecho, profesora de derecho internacional)

En relación con la presentación por el gobierno Perú de una demanda contra Chile en la Corte Internacional de Justicia, en enero de 2008, para que se determinara el limite marítimo entre los dos países, coincido con la posición que resalta los elementos jurídicos del fallo, pero estimo que también deben 
considerarse otros aspectos extrajurídicos involucrados en la secuencia de hechos ocurridos desde entonces.

Personalmente evalúo esta controversia con una mirada positiva. En el caso peruano, tanto en la ciudadanía como en los ámbitos políticos y diplomáticos prendió la idea de que había que resolver una suerte de "hipoteca" pendiente, puesto que el statu quo existente respecto del límite marítimo venía siendo cuestionado desde hacía tiempo. Por eso se llevó adelante el proceso ante La Haya con la convicción de que era necesario solucionar el impasse en forma permanente y definitiva. Para lograrlo, se utilizaron los mecanismos de solución pacífica de controversias que brinda el derecho internacional, vale decir, se abordó esta controversia con una perspectiva diferente de la existente en tiempos pasados. La demanda no fue bien recibida en Chile y el primer gobierno de Michelle Bachelet consideró que se trataba de un gesto inamistoso.

Asimismo, debo mencionar que --al menos formalmente-en Chile nunca se aceptó que podría darse una política de “cuerdas separadas”, mientras que en el Perú se pensaba que era posible estar litigando en La Haya, presentando las distintas perspectivas jurídicas, históricas y políticas y al mismo tiempo seguir avanzando positivamente en la relación bilateral e insistió en que se podía llevar adelante una política de esta naturaleza. Ello constituyó una señal importante avalada por la propia realidad: la tensión en las relaciones bilaterales fue reduciéndose poco a poco y los dos países avanzaron en un proceso positivo.

Por más importante que haya sido fijar el límite marítimo en forma definitiva sin pérdida de vidas que lamentar, a mi juicio en La Haya también se ganó efectivamente un acercamiento entre las partes, con la consiguiente generación de confianza mutua y el avance hacia un camino de integración entre Chile y Perú. Indudablemente tendríamos que estar caminando en esta línea ya trazada.

En días pasados me puse a revisar las visitas reciprocas de Jefes de Estado y altas autoridades realizadas desde 2008 hasta la actualidad y constaté que fueron muchas y muy significativas, incluyendo las declaraciones emitidas en cada 
caso. También se activaron mecanismos de cooperación que estaban congelados

En este tiempo "post La Haya" debemos rescatar esa institucionalidad existente, no necesariamente para reinventarla, sino para dinamizar, actualizar y en algunos casos llenarla de contenidos nuevos. También debería darse continuidad a una serie de instancias que se han creado a nivel de la sociedad civil, como el Grupo de Generación de Diálogo Chile-Perú establecido por este Instituto de Estudios Internacionales de la Universidad de Chile y el IDEI de la Universidad Católica del Perú. Paradójicamente, a partir de la demanda en la CIJ se activó un conjunto transversal de temáticas e instancias del relacionamiento bilateral: los dos gobiernos, los parlamentos, los empresarios, la sociedad civil y el mundo académico se comportaron a la altura de países del siglo XXI, dando muestras de buena vecindad, en forma madura y respetuosa. Todo esto es alentador para ambos países.

Sin perjuicio del análisis jurídico del fallo de La Haya-- con los" mas" y los “menos" que se evalúan en cada país-- hay que avanzar en los signos positivos de una relación que caló profundamente en ambas naciones. Reitero que mi apreciación del proceso es positiva. El acercamiento del Perú y Chile hace posible abordar las relaciones bilaterales a partir del inmenso caudal de posibilidades en los más diversos campos.

Cabe agregar además que para el Perú la sentencia fue trascendente porque contribuyó de alguna manera a sanar heridas del pasado, que datan de un conflicto como fue la Guerra del Pacifico, que dejó secuelas dolorosas.

Algo parecido sucedió en el caso del Perú con Ecuador. Los peruanos teníamos un problema en nuestra frontera norte. Los ecuatorianos se sentían disconformes con el Protocolo de Rio de Janeiro, tratado de límites celebrado en 1942. Tras décadas de intercambios armados, se llegó a la convicción de que convenía negociar un acuerdo de paz integral que incluyó la cesión a Ecuador de un espacio territorial no soberano --el terreno de Tiwinza, de $1 \mathrm{~km} 2$-- para que los ecuatorianos rindieran homenaje a los soldados que perdieron la vida en el conflicto armado de 1995, tomando como modelo los cementerios de guerra que, por ejemplo, tiene Estados Unidos en Normandía (Francia). Además, Ecuador logró acceso y 
libre tránsito por el rio Amazonas. Es así como a partir del Acta de Paz de Brasilia y acuerdos de 1998, se restablecieron las relaciones bilaterales, al punto que actualmente tenemos un gabinete binacional, independientemente del signo político de los gobiernos y se ha podido avanzar muchísimo en la integración de las poblaciones fronterizas.

No puede negarse que cada situación posee su propia lógica, pero si se tiene en cuenta este antecedente, cómo dudar que podemos tener una relación fructífera con Chile, ahora que están resueltas las divergencias por el límite marítimo.

En el escenario actual, otro punto que quiero resaltar es que debe promoverse un mayor acercamiento en el amplísimo ámbito de la sociedad civil. A veces es allí donde subsisten muchos de los resquemores y resentimientos. Por ello es que estoy plenamente de acuerdo en que debe lograrse que nuestros pueblos trabajen en conjunto. Se han desarrollado iniciativas muy interesantes a nivel educativo, cultural y de intercambio científico. Porque, aunque son esenciales, no bastan las relaciones oficiales -Poder Ejecutivo, Parlamento y mecanismos como el Consejo de Integración Social, el 2+2 (Reunión de Ministros de Defensa y Cancilleres), sino que hay que dar relevancia a los grupos de dialogo académico, de mujeres, de estudiantes, de las iglesias y, por supuesto, a los esfuerzos del sector empresarial, incluidas las cámaras de comercio. Todos deben seguir contribuyendo con su valioso aporte.

En el área económica, cabe resaltar que Chile ha invertido más de doce mil millones de dólares en el Perú y este, casi 9 mil millones en Chile. Los empresarios peruanos tienen gran interés en venir a Chile y viceversa porque nuestros países ofrecen buenas oportunidades. Y, por cierto, está el aporte de miles de trabajadores migrantes peruanos en Chile y la gran movilidad de personas entre Tacna y Arica, todo lo cual hace más urgente la integración y los proyectos de desarrollo en conjunto.

En el ámbito regional, cabe mencionar la convergencia de intereses que tenemos en el esquema de la Alianza del Pacifico. Entonces, definitivamente, hay un enlazamiento, una integración, que viene desde abajo, desde la sociedad civil, del sector empresarial y económico, tanto a nivel interno como 
internacional. Por supuesto, hay que incentivar más estas iniciativas y tendencias.

Más allá de lo ya señalado, me inclino a expresar una apreciación crítica respecto del manejo de las relaciones bilaterales por parte del actual gobierno de Chile. Es una pena que el proceso que existía se haya estancado. La dinámica positiva está perdiendo impulso. Si bien se dirá que todo ello por cierto se relaciona con la implementación del fallo, estimo que también tiene que ver con una visión distinta de las relaciones internacionales. Por ejemplo, buscando referencias de la presidenta Bachelet sobre el tema de La Haya, destacan dos expresiones: una de 2008 en que consideraba que la demanda había sido un acto inamistoso y, después de la sentencia, en enero de 2014, su declaración de que el fallo era una pérdida dolorosa para Chile. En cuanto al Canciller Heraldo Muñoz, solamente ha hecho referencias puntuales y ha enfatizado los temas pendientes para la implementación del fallo, incluso declarando que el Perú debería modificar su Constitución para adecuarse a la CONVEMAR. Lamentablemente no ha tenido la información correcta sobre este asunto. Hay que preocuparse de que la conducta verbal, los símbolos e imágenes, sean acertados.

No debe desaprovecharse el punto de inflexión que significa esta etapa post-La Haya. La implementación integral del fallo no tardará en culminarse. Desde el punto de vista internacional, se ha cumplido diligentemente con la fijación de las coordenadas de la nueva frontera marítima mediante el trabajo ejemplar realizado conjuntamente por los equipos técnicos de las Armadas, tanto de Chile como del Perú, sellado en Lima el 24 de marzo pasado en un Acta suscrita por la embajadora María Teresa Infante, Directora de Fronteras y Límites de la Cancillería chilena y Nicolás Roncagliolo, su contraparte en Perú, en presencia de la Canciller Eda Rivas. Lamentamos que la firma de este documento fundamental no hay tenido mucha difusión en la prensa chilena. Sin embargo, el hecho de fijar las coordenadas fue esencial, dado que ahora se sabe a ciencia cierta y con exactitud meridiana cuando se estará cruzando el mar territorial o la zona económica exclusiva de cada país. Y esto es parte fundamental de la implementación de la sentencia de La Haya. Naturalmente, en ambos países 
falta completar la legislación necesaria con el nuevo límite marítimo (en el caso de Perú, entiendo que en el Congreso se avanza en este sentido). Esta formalidad no implica que no se apliquen las disposiciones de la CONVEMAR, porque aunque el Perú no sea Estado-parte de dicho tratado sus normas rigen también por la costumbre internacional. Por otra parte, el hecho de que el artículo 54 de la Constitución peruana de 1993 se refiera al "dominio marítimo", no es contrario a la CONVEMAR. El término permite respetar las 12 millas de mar territorial, las 24 millas de zona contigua y las 200 millas de zona económica exclusiva, así como las libertades y derechos de paso de los terceros Estados. A mayor abundamiento, Alan Wagner, agente del Perú ante la Corte Internacional de Justicia en el caso, aclaró ante los jueces que la Constitución peruana reconoce la existencia de los espacios marítimos y las libertades de tránsito estipuladas en la Convención.

En el Perú, para terminar de implementar internamente el fallo, se han dictado tres decretos supremos y está por aprobarse una nueva ley de bases de acuerdo con el nuevo límite marítimo, respetando la zona económica exclusiva y la libertad de paso de buques chilenos y de terceros Estados. En consecuencia, en la práctica se está cumpliendo lo que establece el fallo de La Haya.

A mi juicio, la agenda bilateral no debería detenerse porque el Perú o Chile no hayan aprobado aún las leyes internas pertinentes. Si mientras duró el litigio ante la Corte pudimos aplicar la estrategia de "cuerdas separadas", no tiene sentido que ahora se paralice la relación en espera de que se dicten normas internas.

Por cierto, hay dos niveles para la acción cuya lógica es diferente. Por un lado, el nivel social, cultural, empresarial, de los inmigrantes y de las inversiones, plano en que las cosas siguen su marcha. Pero a mi juicio, en el nivel político y diplomático, debería darse un matiz diferente a las declaraciones del actual gobierno. Tengo gran admiración y aprecio por el Canciller Muñoz, pero confieso que me sorprende que se haya referido solamente a la implementación del fallo como prerrequisito de la relación bilateral. Sin duda ella es importante y es preciso completar todo el proceso, hasta la inscripción 
del acuerdo en las Naciones Unidas, para pasar luego a otra etapa de la relación. Durante el gobierno pasado en Chile se puso mucho énfasis en el Perú y poco en el resto de América Latina, gracias a lo cual se dinamizó aún más la relación entre ambos. En cambio, ahora se habla de privilegiar otros países, como Brasil o Argentina, y de acercar la Alianza del Pacífico al Mercosur. Eso está muy bien, pero desaprovecha el momento respecto del Perú, con el cual hay que avanzar en los dos niveles, sin dejar de lado la dinámica social y de las inversiones económicas. Desde fuera, lo que se observa es que en cierta medida se deja un poco de lado lo que significa haber llegado al término del litigio con el Perú. En definitiva, creo que no debieran detenerse ni obstaculizarse la política de integración y la "agenda post- La Haya". Los temas en que aún subsisten discrepancias --como el relativo al triangulo terrestre-- pueden y deben tratarse y solucionarse a nivel diplomático.

A mi juicio no debería desperdiciarse el momentum postLa Haya, sino avanzar sin demora en activar la institucionalidad existente y los proyectos integradores en esta nueva etapa enmarcada en una era global y digital que requiere actuar en conjunto.

Coincido en la importancia de la conducta verbal, esto es, en los símbolos y las imágenes, por eso creo que hay dos dinámicas diferentes y hay que actuar en los dos niveles señalados.

\section{ASTRID ESPALIAT}

(Miembro del Grupo asesor de la Cancillería en el diferendo entre Perú y Chile, profesora de derecho internacional del Instituto de Estudios Internacionales y de la Academia Diplomática Andrés Bello)

Quisiera partir señalando que la relación entre Chile y Perú está fuertemente enmarcada en el cumplimiento del fallo dictado por la Corte Internacional de Justicia 
Si bien es efectivo que en el transcurso de estos años se han desarrollado nuevos vínculos entre ambos países a partir de la importante migración de peruanos a Chile, así como del desarrollo del comercio y las inversiones, el núcleo de la relación entre ambos Estados está determinada por las decisiones adoptadas por ellos en el ámbito de sus respectivos gobiernos, en las que ocupa un lugar relevante el cumplimiento de una sentencia que puso fin a una controversia que mantuvo enfrentados durante seis años a Chile y Perú. No obstante que en los últimos años se aplicó una política de cuerdas separadas que permitió el desarrollo de las relaciones con el Perú en distintos ámbitos, ello en nada eliminaba la tensión que es consustancial al desarrollo de una diferencia ante la Corte Internacional de Justicia.

El cumplimiento del fallo es, por tanto, una cuestión de la mayor relevancia para el adecuado desarrollo de las relaciones futuras de Chile y Perú. El párrafo 178 de la sentencia indica, a mi juicio, un claro camino a seguir por el Perú. Dicho párrafo indica que el agente de Perú declaró formalmente en nombre de su gobierno que la expresión “ dominio marítimo" que figura en la Constitución peruana es utilizada de conformidad con la definición de espacios marítimos prevista en la Convención de 1982. Agregó que la Corte tomaba nota de esta declaración que expresa un compromiso formal del Perú. A mi juicio, la Corte vincula la declaración del agente del Perú a los efectos que en derecho internacional tienen las declaraciones de los representantes de un Estado: generación de obligaciones jurídicas en relación con comportamientos futuros.

Perú está dando algunos pasos para cumplir con lo ordenado por la Corte, pero no deja de inquietarme que esos pasos se hayan traducido en la elaboración de tres reglamentos para la Armada de Perú y la dictación de simples decretos. Además de que se trata de instrumentos que se pueden modificar de un día a otro, pues son instrumentos creados por el Ejecutivo, llama la atención que mediante un decreto se modifique o se intente modificar el texto de una ley, como es el caso de una ley que regula la aeronavegación civil. No discuto que haya voluntad de avanzar, pero tengo la impresión de que el avance no tiene lugar por un camino claro, que otorgue certidumbre y permita avanzar en un proceso de creación de confianzas 
que es fundamental para abordar los problemas y desafíos que plantea toda relación vecinal. Si bien el camino de promulgar leyes en cumplimiento del fallo es más largo y difícil, pues obliga a someterlo a discusión en el Congreso, es por esta razón el único que aportaría una mayor certeza a las medidas que Perú debe tomar para ejecutar con lo preceptuado por el fallo: cumplir con las reglas de la Convención de las Naciones Unidas sobre el Derecho del Mar.

Considero que los cambios realizados son débiles. Es posible que se den pasos significativos y positivos tras la evacuación del informe de la Comisión creada por el gobierno del Perú para determinar las consecuencias del fallo de la Corte respecto de las líneas de base, de 2005. Se trata una comisión intersectorial integrada por un amplio espectro de personas, desde diplomáticos hasta miembros de las Fuerzas Armadas, cuyo cometido es elaborar esas consecuencias del fallo y que también revisó lo relativo al espacio aéreo de acuerdo con lo previsto en el artículo 54 de la Constitución política del Perú. Ese informe se tendría presente para elaborar la ley que debe modificar la Ley de Base de Dominio Marítimo de 2005, ello en virtud de los dispuesto por la Corte Internacional de Justicia.

La construcción de bases sólidas en la relación entre ambos Estados es indispensable para avanzar en el proyecto de integración que se ha planteado en la Alianza para el Pacífico. La Alianza constituye un proyecto novedoso porque a partir de una base común, la existencia de tratados de libre comercio entre todos sus integrantes, estos se han propuesto metas más ambiciosas: avanzar progresivamente hacia la libre circulación de bienes, servicios, capitales y personas; impulsar un mayor crecimiento, desarrollo y competitividad de sus economías, así como convertirse en una plataforma de articulación política, de integración económica y comercial, para proyectarse al mundo, con énfasis en la región Asia-Pacífico. Ya se detectan avances importantes, como el significativo aumento de las importaciones no tradicionales entre Chile y Perú. Para Chile, la Alianza del Pacífico sigue siendo un proyecto relevante, si bien el actual gobierno ha introducido la idea de que ese Acuerdo no debe entenderse como un instrumento que excluye a otros países y acuerdos de integración de la región. No es posible seguir generando instancias de integración que se diluyan 
en el tiempo, como lo exhibe la historia de la región. Pero el avance de todo proyecto de integración requiere claridad en las reglas del juego. En este sentido, ello nos reconduce al cumplimiento del fallo de la CIJ. Las señales que ha dado el actual gobierno de Perú respecto de esta cuestión hasta el momento no son para nada claras. Entonces, cabe preguntarse si existe preocupación real por cumplir el fallo, por eliminar las dudas y tensiones existentes y por profundizar la relación entre Perú y Chile.

\section{HERNÁN FELIPE ERRÁZURIZ}

(Ex Canciller, abogado, analista internacional)

La verdad es que las dificultades sobre la implementación del fallo sobre delimitación marítima con Perú que he escuchado en esta reunión no corresponden a lo que se percibe desde fuera. En el mundo de los negocios y en la prensa se anticipa un cumplimiento del fallo sin mayores problemas. Por mi parte, confío en que este proceso se llevará oportuna y civilizadamente. Si hubiese alguna demora y surgieren obstáculos que obedezcan a mala intención de alguna de las partes, las consecuencias serían muy negativas. Felizmente, hasta ahora nada de eso ha sucedido y hay confianza en la forma en que están procediendo los técnicos y la diplomacia. A mi juicio, mientras no se den señales de preocupación, se avanzará sin tropiezos. Me parece que ha quedado demostrado que la relación entre ambos países es fuerte y dinámica.

En rigor, si se quiere poner fecha a las dificultades en la relación Chile- Perú que culminaron en la demanda ante el tribunal de La Haya, hay que remontarse al asunto de los grafiteros, a los supuestos espionajes, a Aerocontinente y a los problemas que enfrentaron las inversiones chilenas después de Fujimori, cuando asuntos de particulares se transformaron en problemas de Estado. Por absurdo que parezca, entonces vivimos una época de sensibilidad extrema en que muchas 
de las situaciones que se produjeron fueron repercusiones de un pasado bastante lejano, a la persistencia de resquemores provocados por hechos resueltos jurídicamente que a menudo condujeron a problemas explotados artificialmente. Hay diversos ejemplos de esto, conocidos de todos, y me atrevo a decir que muchas veces los desencuentros fueron ocasionados o promovidos por el oficialismo peruano. Pero no vale la pena detenerse en lo ocurrido durante los gobiernos de Paniagua y Toledo. Esto me lleva a concluir que si el fallo sobre la cuestión del límite marítimo se cumple de buena fe, con normalidad, con el elemento básico de la confianza recíproca, en el futuro no debería haber problemas bilaterales mayores. En cambio, si llegara a percibirse que los sectores nacionalistas del Congreso y de la Cancillería peruana quieren hacer una pequeña trampa y mantener pendiente asuntos territoriales se retrocedería en todo lo avanzado en las relaciones políticas y con repercusiones en las económicas, que desde hace años van corriendo por otro carril.

Por esa razón, es indispensable hacer bien las cosas, que haya coordinación, que el procedimiento para cumplir con la sentencia sea claro y expedito. La prueba de la confianza que debe imperar es el avance en los campos diplomático, económico, de las migraciones, de la seguridad y de la cultura. Pero hay mucho que avanzar aún. Por ejemplo, a mi juicio, el día que se produzca la integración energética con el Perú habríamos llegado a otra etapa de la relación. Al respecto, cabe recordar nuestra mala experiencia con Argentina, en que la integración energética fracasó por decisión unilateral del presidente Néstor Kirchner y en que a mi juicio debimos dar una señal totalmente distinta a la mera tolerancia que dieran los gobiernos de la Concertación por el incumplimiento del protocolo gasífero. Más importante, junto con acordar la compra de gas a Argentina, debimos haber tomado resguardos oportunamente y no esperar el corte del gas para contar años después con la planta de GNL en Quintero y Mejillones. Esta experiencia no debemos olvidarla para no repetir los mismos errores.

Para apreciar la calidad de la relación entre nuestros dos países habría que partir por hacer una lista con los temas económicos, sociales, de seguridad, culturales y políticos, que 
son determinantes para medir los lazos bilaterales. En el caso del fallo que nos reúne hoy me da la impresión de que no estamos haciendo esa lista. Quizá esto obedezca a que recién comenzamos a tomarle el peso a la sentencia y no nos estamos fijando metas a ninguno de los dos lados de la frontera. Es un hecho que nuestra relación con el Perú debería ser mucho más intensa y más densa de que la que tenemos actualmente. Hay cosas que realmente no puedo comprender, como la lentitud en avanzar, la incompetencia al abordar diversas materias que parecen tan obvias.

Por ejemplo, me impacienta que no se avance en el tema de las migraciones, en el que he estado trabajando. Se sigue postergando legislar sobre el tema sin considerar que hay sobre 200 mil inmigrantes peruanos, miles trabajando indocumentados y un $10 \%$ en extrema pobreza que requieren de programas sociales y de regularización cuya ausencia podría tener indeseables repercusiones internas y para las relaciones bilaterales. Viene al caso mencionar que hay condiciones favorables actualmente para legislar sobre la materia y que no es tan seguro que se mantengan a futuro. Es positivo que en la última encuesta Bicentenario de la Universidad Católica y El Mercurio, sobre la tolerancia de los migrantes, se comprobara que en Chile hay una tolerancia razonable y mayor que en Europa, donde avanza la xenofobia. Esto se comprueba con la reacción de los chilenos frente a los migrantes peruanos cuando se dictó el fallo. Las aprensiones sobre las posibles reacciones nacionalistas y adversas a la comunidad peruana residente, resultaron equivocadas.

A futuro me preocupa la elevada posibilidad de que la inmigración peruana aumente en forma demasiado masiva y no nos hubiésemos dotado de una institucionalidad adecuada. La legislación actual, que data de 1974, es totalmente anacrónica y si dentro de unos cinco años la inmigración llegara a cifras de 300 mil y si la economía no está en un ciclo expansivo, la migración podría ser resistida y podríamos tener medidas restrictivas que son friccionantes. Hay que legislar prontamente.

También me inquieta que se detuviera el positivo intercambio de académicos, prensa, políticos y de la comunidad de negocios chileno- peruana que fuera muy intensa durante el juicio en La Haya. 
También hay que tener en cuenta las negativas señales del gobierno actual de inclinarse en perjuicio de la Alianza del Pacífico, hacia UNASUR y MERCOSUR, con la idea de promover la impracticable convergencia entre la Alianza y este último. Ese intento es inconducente y solo puede degradar a la Alianza del Pacifico. El modelo proteccionista del MERCOSUR está obsoleto en un mundo globalizado y comienza a ser resistido en Brasil. Además, esa pretensión de armonización es contraria a nuestra política de Estado en favor del libre comercio y un obstáculo a las relaciones con Perú que tiene como uno de sus ejes a la Alianza del Pacifico, que por lo demás en un par de años ha sido más exitoso que los casi 20 del MERCOSUR

En el comercio y la inversión binacional que avanza sostenidamente. Los grandes grupos económicos chileno y peruano están invirtiendo considerable y diversificadamente en los dos países. Las exportaciones crecen a tasas significativas. Chile exporta más a Perú que a Argentina y si se deducen las exportaciones de minerales, más que a Brasil, economías tres y siete veces más grandes que la peruana. Aunque es un hecho que en determinados sectores empresariales del Perú se observa una resistencia a la inversión chilena en ese país. En cambio, en Chile nunca se da la misma resistencia respecto de la inversión peruana. Aquí no se pregunta por qué le interesa invertir en nuestro territorio. Simplemente se considera a la peruana como una inversión extranjera más.

Finalmente, hay que mencionar las relaciones castrenses que de acuerdo con las informaciones de que dispongo no experimentan progreso.

Uno de los aspectos novedosos de este ejercicio a que nos ha llamado la revista Estudios Internacionales es la oportunidad de escuchar a diversos profesionales referirse al fallo desde distintos ámbitos. Ello permite formarse un panorama general de sus proyecciones que enriquece las propias conclusiones. Confío en que en el futuro continuará esta línea de trabajo con el examen de otros temas igualmente interesantes. 


\section{FANOR LARRAÍN}

(Director Asia-Pacífico, UCV)

Después de escuchar lo expresado hasta aquí debo reconocer que yo abordé el tema del fallo de La Haya desde una perspectiva diferente, considerándolo como el inicio de un largo proceso, porque el gran desafío que enfrentamos es cómo se cumplirá y eso puede tardar años. Comencé por preguntarme si las instituciones internacionales pueden transformar los intereses de los Estados, si en estos ha evolucionado el tema de la soberanía y si la nueva institucionalidad será capaz de transformar las prácticas soberanas de manera de lograr que evolucione la cooperación y que ambos Estados adopten prácticas estratégicas. En suma, si lograrán superarse los conceptos de "quién ganó" y "quién perdió". Desde luego, hay temas pendientes y uno de ellos consiste en ajustar la legislación interna del Perú de acuerdo con el derecho internacional del mar consagrado en la CONVEMAR, de 1982 e incorporarlo en su Constitución. Por ahora, solo lo ha hecho de manera provisional, mediante un decreto. En todo caso, veo disposición de ambas partes a cumplir con lo establecido en el fallo $\mathrm{y}$ al parecer han comenzado a construirse nuevas ideas sobre cómo articular nuevos consensos que respondan a los intereses e identidades de Chile y del Perú. En rigor, las peores amenazas que entorpecen el avance corresponden a variables internas de cada gobierno, que se mantengan "latencias nacionalistas" para obtener beneficios políticos y que persistan las tensiones entre nacionalistas y cosmopolitas. Cabe preguntarse si aun después del fallo de la Corte el tema de los límites marítimos podrá llevar a que surjan otros litigios, latentes o pendientes, por lo cual habrá que seguir de cerca los discursos y ver si emergerán nuevos significados e interpretaciones.

Las prácticas del pasado son reproducidas, apropiadas, desplazadas y cambiadas por las prácticas y el contacto cotidiano de los actores. El fallo es una oportunidad de salir de la lógica de las dos guerras mundiales del siglo XIX y mirar de 
cara al siglo XXI. Esta labor de día a día sobre la herencia del pasado abre el camino para apuntar hacia el futuro y llegar a una conciencia práctica y pragmática. Es preciso que Chile y el Perú se pongan de acuerdo sobre un número reducido de principios y competencias capaces de crear múltiples respuestas que en definitiva conduzcan a una diplomacia creativa regida por las normas del derecho internacional. Se trata de aprovechar el capital que han invertido ambos Estados y crear situaciones nuevas dentro del espacio de los posibles para lograr una relación positiva.

El interés nacional no es solo material y utilitario sino también simbólico. Para el Perú su reclamo se tradujo en un logro; para Chile, el prestigio de acatar un fallo que le resta soberanía lo enaltece como actor confiable en el ámbito internacional.

Es posible que las normas de legitimidad reconocidas por los actores estén muy alejadas de las normas escritas. Cabe preguntarse si Chile y el Perú seguirán compartiendo las mismas normas y valores contenidos en el fallo y si podría esperarse que con el tiempo surja una cultura internacional del Pacífico latinoamericano, como sería el caso de la Alianza del Pacífico. Aunque en la política internacional seguirán importando el poder y los intereses, el conocimiento recíproco y los valores compartidos, unidos a la experiencia de haberse sometido a un tribunal internacional determinarán lo que significa optar entre el equilibrio y la cooperación, o el conflicto. Para ello es preciso investigar y reunir información y evidencia acerca de los intereses, motivaciones e identidades nacionales en materia de seguridad y cooperación, y no basarse exclusivamente en el cálculo racional.

Una interrogante que hay que enfrentar es si de la reiterada interacción de diplomáticos, militares y empresarios habrán de surgir nuevas interpretaciones y significados del fallo y cuál es el peso que tiene en ello la sociedad civil.

A mi juicio, habrá que observar de qué manera cada uno de los Estados definirá la situación en relación con metas, amenazas, temores, culturas, identidades y otros elementos de la realidad social y política. El lenguaje y la retórica nos entregarán elementos para apreciar cómo se irá implementando el fallo y construyendo una nueva realidad. 


\section{JOSÉ MIGUEL POZO}

(Historiador, miembro del Ministerio de Relaciones Exteriores).

La verdad es que son muchos los temas sobre los cuales sería interesante dialogar, pero comenzaré por referirme al hecho de que en el Perú, en distintas oportunidades, desde el presidente de la República hasta la prensa expresaron dudas de que en Chile acataríamos el fallo. Esto no deja de llamar la atención, porque nos hemos caracterizado por cumplir los fallos de los tribunales, por desfavorables que sean para nosotros. En este sentido, hasta podría tachársenos de ingenuos y resulta que al cabo de una semana estuvimos dispuestos a dar cumplimiento al fallo de la CIJ, a partir de la reunión 2 + 2 con Perú en la que se establecería de común acuerdo la ubicación exacta de las nuevas coordenadas de acuerdo al tenor de lo dispuesto por la Corte Internacional de Justicia de la Haya en su fallo de 27 de enero de 2014.

Si queremos comprender la génesis de toda esta situación, debemos concluir que ella obedeció a una reacción de nuestros vecinos respecto de una guerra con Chile que tuvo lugar hace largo más de cien años. Felizmente, en este adverso contexto, la sociedad civil reaccionó muy adecuadamente y no se advirtió resentimiento por parte de ella; por el contrario, comenzó a interesarse en iniciativas académicas como en el caso del diálogo organizado por este Instituto de Estudios Internacionales junto con instituciones homónimas del Perú. A partir de entonces, la relación fue mucho más dinámica. Ahora bien, desde el punto de vista histórico, me llaman la atención la presencia y permanencia de los temas de índole limítrofe. Cuando estudié historia, el tema de los límites estaba superado porque se consideraba que pertenecían a coyunturas propias del siglo XIX. Pero me doy cuenta de que en la práctica, este tema no ha sido superado, y lo vemos en el caso de la papelera entre Uruguay y Argentina. También se da en los pleitos de Honduras y Nicaragua, de Nicaragua y Colombia y de Bolivia y Chile. A mi juicio, en la relación entre países 
vecinos más allá de lo territorial hay aspectos ambientales e incluso sicológicos de los que hay que preocuparse.

A continuación, querría referirme a la reiterada crítica que se hace al Ministerio de Relaciones Exteriores de Chile, en el sentido de que antes de que el Perú recurriera a la Corte Internacional de Justicia debió negociarse una salida al mar de Bolivia. Como lo expresara hace unos minutos muy claramente la embajadora Infante, a Chile no le cabía otra estrategia que defender la existencia de un límite marítimo, por lo que la defensa de Chile debía articularse desde un ángulo jurídico, ante lo cual no correspondía negociar sino que defender la existencia de los tratados en vigor de 1952 y 1954. En ese sentido, y ante la intempestiva demanda peruana, Chile como ya lo he expresado se abocó a su defensa jurídica, mientras que con Bolivia la relación se enmarca en la mesa de los 13 puntos, incluyendo el punto seis marítimo. De manera entonces, que cada parte actuó como entendió que tenía que actuar de acuerdo con sus intereses.

Volviendo sobre lo dicho acerca del punto de vista histórico, en este juicio cuyo fallo estamos examinando, hubo mucho de simbólico que arranca de la guerra del Pacífico y de lo sucedido con Tacna y Arica, que creó tensión y se resolvió recién en 1929. De ahí hasta 1952 hubo acuerdo al crearse el concepto de soberanía sobre las 200 millas, pero la tensión se renovó al conmemorarse el centenario de la guerra del $\mathrm{Pa}$ cífico. Luego, en 1999 se produjo la entrega de las obras del puerto de Arica, que era el punto pendiente. Se comprueba así que se va desarrollando una mentalidad menos agresiva y por eso cuando se dio a conocer el fallo no se produjo ningún incidente importante. En cuanto a lo que suceda en el futuro, todo indica que la densa relación económica - social con Perú permitirá que se construya en el futuro una vinculación mucho más beneficiosa para peruanos y chilenos, y todo ello en función de una estrategia económica coincidente con el Perú, cuyo punto culminante es la Alianza del Pacifico, ante lo cual cabe esperar que la relación con Perú en un futuro cercano se normalice plenamente.

Ahora bien, y respondiendo a la inquietud planteada por nuestra querida colega Beatriz Ramachiotti, no hay que eludir el hecho de que actualmente con el Perú ha surgido otra 
diferencia territorial vinculada al comienzo de la frontera terrestre, lo que ellos denominan el triángulo terrestre. No obstante, que la Corte Internacional de Justicia consignó que el punto de partida de la frontera marítima entre Chile y Perú es la intersección del paralelo de latitud que pasa por el Hito 1 con la baja marea, Perú considera que esto no implica que el Hito $\mathrm{N}^{\circ} 1$ sea el comienzo de la frontera terrestre, postulando que el inicio de la línea fronteriza chileno - peruana debe convenirse. $\mathrm{Al}$ respecto, Chile tiene bien en claro que el asunto se resolvió en 1930, cuando se demarcó íntegramente la frontera chileno peruana de acuerdo con lo estipulado en el Tratado de Lima de 1929 y lo señalado en las Actas Demarcatorias de los Plenipotenciarios y de los Ministros de mediados del decenio de 1930. A mayor abundamiento, al ser derogado recientemente por ley peruana el punto 266, ya no se puede hablar de un triángulo en disputa. Con todo y no obstante esta diferencia, estamos esperanzados en que ella no empañe el futuro de nuestras relaciones, de modo que más temprano que tarde, logremos con nuestros vecinos una relación óptima.- 